\title{
Rancang bangun alat two phase flow (air-udara) sebagai media pembelajaran dan praktikum mahasiswa skala laboratorium
}

\author{
Gunarto $^{1^{*}}$, Waspodo², Doddy Irawan ${ }^{3}$, Eko Julianto ${ }^{4}$ \\ 1,2,3,4Program Studi Teknik Mesin, Fakultas Teknik, Universitas Muhammadiyah Pontianak \\ JI. A.Yani No.111 Pontianak, Kalimantan Barat, Indonesia \\ *Corresponding author: guncici75@gmail.com
}

\begin{abstract}
The purpose of this research is to produce a two-phase flow tool as a learning media and practicum based on the engineering approach (BPRT) to increase student motivation, abilities, skills, and understanding of two-phase flow courses. The research stages were carried out by designing the design and manufacturing or assembling of two-phase flow tools with horizontal and vertical orientations into a complete unit, as well as testing the tools so that they can be used for practicum. Data collection and retrieval were adjusted to the test instruments. The results of this research is a learning media tool and practicum to test the characteristics, determine or look for a pressure drop, and a two-phase flow pattern. This two-phase flow device can operate in horizontal and vertical pipe test sections with minimum water and air flow rate of $0.00017 \mathrm{~m}^{3} / \mathrm{s}$ or 600 liters/hour while a maximum of $0.0005 \mathrm{~m}^{3} / \mathrm{s}$ or 1800 liters/hour. The minimum pressure allowed on this tool is 0.3 bar and the maximum is 0.83 bar.
\end{abstract}

Keywords: two phase flow, pressure drop, flow pattern, practicum

\section{Abstrak}

Tujuan penelitian ini adalah menghasilkan sebuah alat aliran dua fase sebagai media pembelajaran dan praktikum yang Berbasis Pendekatan Rekayasa Teknik (BPRT) untuk peningkatan motivasi belajar, kemampuan, skill dan pemahaman mahasiswa terhadap mata kuliah aliran dua fase (two phase flow). Tahapan penelitian dilakukan dengan perancangan desain dan pembuatan atau perakitan alat aliran dua fase dengan orientasi horisontal dan vertikal menjadi satu kesatuan yang utuh, serta pengujian alat sehingga bisa digunakan untuk praktikum. Pengumpulan dan pengambilan data disesuaikan dengan instrument alat uji. Hasil penelitian ini adalah sebuah alat media pembelajaran dan praktikum untuk uji karakteristik, penentuan atau mencari penurunan tekanan (pressure drop) dan pola aliran (flow pattern) aliran dua fase. Alat aliran dua fase ini dapat beroperasi pada seksi uji pipa horisontal maupun vertikal dengan debit air dan udara minimum $0.00017 \mathrm{~m}^{3} / \mathrm{s}$ atau 600 liter/jam sedangkan maksimumnya sebesar $0.0005 \mathrm{~m}^{3} / \mathrm{s}$ atau 1800 liter/jam. Untuk tekanan minimum yang diijinkan pada alat ini adalah 0.3 bar dan maksimumnya 0.83 bar.

Kata kunci: aliran dua fase, penurunan tekanan, pola aliran, praktikum

\section{Pendahuluan}

Dalam mencerdaskan anak didik sebagai aset negara perlu mengembangkan sarana dan prasarana dalam menunjang ilmu pengetahuan di lingkungan akademis. Pembelajaran ilmu-ilmu teknik yang sudah berjalan khususnya pembelajaran bidang mekanika fluida aliran dua fase (two phase flow) di Program Studi Teknik Mesin

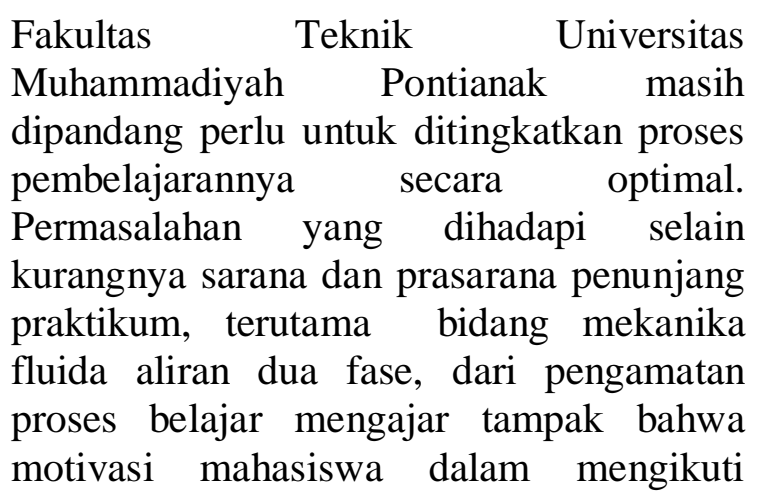


pelajaran masih kurang dan kemampuan mahasiswa untuk memahami materi kuliah aliran dua fase masih rendah dikarenakan merasa kesulitan dalam memahami materi, buku teks, serta modul aliran dua fase. Dalam belajar sangat nampak mahasiswa kurang semangat, kemauan rendah, jarang mau bertanya dan tidak ada upaya untuk mengutarakan ide-idenya terhadap materi yang diberikan. Mahasiswa kurang aktif dalam pembelajaran mata kuliah aliran dua fase.

Mahasiswa jarang mengajukan pertanyaan ataupun mengutarakan idenya walaupun dosen berulang kali mengajukan pertanyaan. Selain itu keaktifan mahasiswa untuk membaca buku referensi juga masih rendah.

Karena begitu rumitnya aliran dua fase ini maka tidak cukup hanya diajarkan secara teori di kelas tetapi perlu adanya media atau perangkat pembelajaran lain untuk meningkatkan pemahaman terhadap materi aliran dua fase ini. Oleh sebab itu perlu untuk mengembangkan perangkat pembelajaran berupa perancangan alat aliran dua fase (two phase flow) sebagai salah satu alternatif dalam upaya peningkatan pemahaman mahasiswa pada pembelajaran dengan program Berbasis Pendekatan Rekayasa Teknik (BPRT).

Keefektifan program pendidikan dapat dilihat dari:

1. Keberhasilan program tersebut sesuai tujuan instruksional yang sudah ditetapkan.

2. Keterlibatan siswa secara aktif sehingga memudahkan dalam mencapai tujuan instruksional.

3. Memadainya sarana penunjang dalam proses pembelajaran [1]

Pemanfaatan dan pemakaian media dalam proses pembelajaran adalah untuk mengefektifkan dan mengefesiensikan proses belajar mengajar itu sendiri [2].

Tujuan dari perancangan alat ini selain dapat dijadikan media belajar untuk peningkatan motivasi belajar, kemampuan, skill dan pemahaman mahasiswa terhadap materi aliran dua fase, juga dapat digunakan sebagai alat praktikum.

Dengan praktikum mahasiswa akan mendapatkan pengalaman belajar, dan mengenal lebih dekat perangkat yang digunakan serta mengamati langsung gejala-gejala yang terjadi pada alat uji aliran dua fase tersebut. Melalui praktek di laboratorium inilah mahasiswa akan lebih dapat memahami materi kuliah dengan melakukan kegiatan nyata.

Dalam penelitian ini penulis membuat alat aliran dua fase (two phase flow) air dan udara dengan kedudukan/posisi horisontal dan vertikal. Seksi uji dengan menggunakan pipa akrilik transparan dengan ukuran yang berbedabeda. Untuk praktikum, alat ini dapat digunakan untuk penentuan atau mencari penurunan tekanan (pressure drop) dan pola aliran (flow pattern).

\section{Tinjauan Pustaka}

Aliran dua fase merupakan bagian dari multiphase flow. Dalam mempelajari aliran dua fase dapat kita perhatikan atas beberapa bagian yaitu atas wujud fasenya, arah dari alirannya dan kedudukan atau posisi saluran. Bila dilihat dari wujud fasenya bisa terdiri dari fase gas-cair, gaspadat, cair-padat. Berdasarkan kedudukan/posisi saluran, ada aliran mendatar (horizontal), aliran tegak (vertical), dan miring. Sedangkan bila ditinjau dari arah aliran dua fase terdiri dari aliran searah dan berlawanan arah. Banyak sekali ditemui aliran dua fase pada geothermal, reaktor, heat exchangers, air lift pump dan bidang industri, seperti pada industri perminyakan, industri pertambangan, pembangkit listrik tenaga uap, industri kimia dimana dalam pemindahan fluida umumnya dilakukan melalui sistem perpipaan $[3,4]$. Di sistem perpipaan, selain penggunaan pipa-pipa utama, terdapat komponen asesoris lain yang diperlukan seperti belokan pipa, sambungan pipa, pengecilan dan pembesaran pipa serta kombinasi dari asesoris tersebut [5]. 
Penelitian tentang aliran dua fase (air-udara) baik dengan orientasi atau kedudukan pipa horisontal maupun vertikal sudah banyak dilakukan. Begitu juga penelitian tentang analisa pressure drop akibat gesekan aliran dua fase yang dilakukan [6,7], dan investigasi pola aliran pada pipa $[8,9]$. Pengaruh kualitas volumetrik dan kecepatan campuran pada penurunan tekanan aliran udara-air dalam pipa horizontal dengan ID yang berbeda diselidiki baik secara eksperimental dan numerik, melalui berbagai korelasi empiris dan dengan menggunakan model drift-flux [10].

\section{Metode Penelitian}

Metode penelitian ini menggunakan desainn eksperimen murni (true experimental research) dengan merancang dan pembuatan alat, pengujian alat.

Alat media pembelajaran dan praktikum aliran dua fase ini dibuat di Laboratorium Teknik Mesin Universitas Muhammadiyah Pontianak, yang terletak di Ambawang Kubu Raya. Alat ini terdiri dari pipa PVC dan akrilik secara vertikal dan horisontal yang terdiri dari 4 (empat) pipa akrilik dengan ukuran 1 inchi dan 1 1/2 inchi dan panjang setiap bagian seksi uji 1 meter, seperti yang ditunjukkan pada Gambar 1 .



Gambar 1. Desain alat aliran dua fase
Keterangan Gambar 1:

1. Pompa Air

15. Selenoid Valve

2. Tangki Air

16. Actuated Valve

3. Pressure Gauge

17. Check Valve

4. Rotometer Air

18. Rotometer udara

5. Elbow $9^{0}$

19. Air Flow

6. Water Flow

7. Unification of

20. Ball Valve water and air

21. Tee fluids

8. Kompressor

9. Manometer Udara

22. Reducer 1 inch

23. Reduser 1.5 inchi

24. Seksi uji 1

25. Seksi uji 2

10. Tangki Udara

11. Ball Valve

12. Knee $90^{\circ}$

26. Outlet Seksi Uji

27. Outlet TJunction

13. Termocouple

14. Control Valve

Alat ini dirakit sendiri dengan mengacu pada referensi penelitian dan artikel terkait serta merupakan satu kesatuan dari komponen-komponen berikut:

1. Dua tangki air dengan kapasitas maksimal 50 liter untuk menampung air yang disirkulasikan.

2. Pompa sentrifugal dengan head 9 meter dan kapasitas 62 L/menit, yang digunakan untuk memompa dan mensirkulasikan air.

3. Kompresor, tekanan maksimum 6 bar berguna untuk menginjeksikan udara yang bersirkulasi dengan air.

4. Tabung udara dengan kapasitas $9 \mathrm{~kg}$ untuk menampung udara yang hendak disirkulasikan.

5. Katup pengatur 1 inchi sebagai pengatur kecepatan aliran yang masuk pipa seksi uji dan by pass agar kecepatan aliran yang bersirkulasi dalam pipa konstan dan menghindari terjadinya water hammer.

6. Rotometer air dengan kapasitas pengukuran maksimal $300-3000$ LPM, digunakan untuk menentukan dan mengukur kapasitas aliran air yang bersirkulasi.

7. Rotometer udara dengan kapasitas pengukuran maksimal 70 LPM, 
digunakan untuk menentukan dan mengukur kapasitas aliran udara yang bersirkulasi.

8. Pressure gauge digunakan sebagai pengukur beda tekanan pada dua titik yang berbeda pada pipa seksi uji.

9. Pipa akrilik dengan diameter luar 1 inchi dan $1 \frac{1}{2}$ inchi, tebal pipa $3 \mathrm{~mm}$, sepanjang masing-masing 1 meter yang digunakan sebagai pipa pengujian.

10. Kamera digital digunakan untuk mengabadikan dan menvisualisasikan aliran air dan udara (campur) yang bersirkulasi.

11. Termometer digital digunakan untuk mengukur suhu pada ruang, benda dan zat.

12. Temperature controller atau thermostat digunakan untuk menjaga suhu air panas yang akan masuk ke pipa dalam agar konstan.

13. Control valve adalah sebagai perangkat untuk mengatur besaran baik aliran, tekanan dan lain-lain.

14. Solenoid valve berguna untuk mengontrol saluran udara yang bertekanan menuju pipa seksi uji.

15. Actuated valve berguna untuk mengkonversi fluida menjadi gerakan mekanis membuka/menutup atau mengontrol sebuah valve.

\section{Hasil dan Pembahasan}

Hasil penelitian dalam perancangan dan pembuatan model media pembelajaran ini didapatkan peralatan untuk praktikum pengujian karakteristik aliran dua fase ( $t w o$ phase flow) di Laboratorium Teknik Mesin Universitas Muhammadiyah Pontianak ditunjukkan pada Gambar 2.

Alat uji ini terdiri dari atas pipa vertikal dan horisontal dengan satu pompa sentrifugal untuk mengalirkan fluida air dan satu kompresor untuk mengalirkan udara dengan motor penggerak yang menyatu pada masing-masing pompa dan kompresor. Instalasi dilengkapi dengan katup-katup pengatur aliran, sehingga memungkinkan untuk membagi debit masing-masing dari pompa dan kompresor.
Pengukuran debit air maupun udara yang masuk pipa uji dilakukan dengan mengukur volume aliran air yang melewati flow meter dan mencatat rentang waktu yang diperlukan untuk mengalirkan volume tersebut.

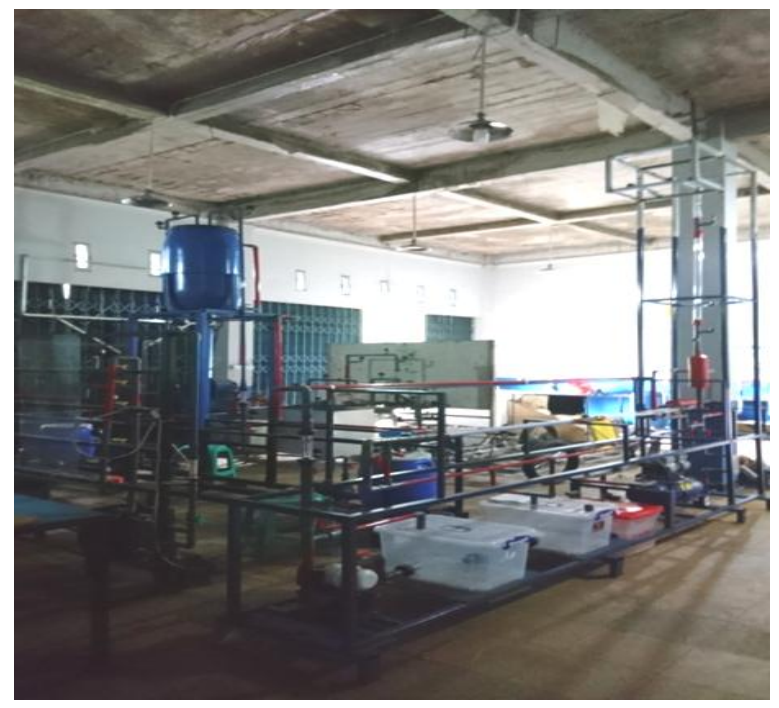

Gambar 2. Alat Two Phase Flow

Pengujian alat praktikum aliran dua fase dilakukan untuk mendapatkan nilai debit air $\left(\mathrm{Q}_{\text {air }}\right)$, debit udara $\left(\mathrm{Q}_{\text {udara }}\right)$, tekanan (P) minimum dan maksimum yang melalui seksi uji pipa horisontal maupun vertikal. Data penelitian ditunjukkan pada tabel 1 .

Tabel 1. Data hasil pengujian

\begin{tabular}{cccc}
\hline No & $\begin{array}{c}\text { Debit Air } \\
\mathrm{m}^{3} / \mathrm{s}\end{array}$ & $\begin{array}{c}\text { Debit Udara } \\
\mathrm{m}^{3} / \mathrm{s}\end{array}$ & $\begin{array}{c}\text { Tekanan } \\
\text { Bar }\end{array}$ \\
\hline 1 & 0.00017 & 0.00017 & 0.3 \\
2 & 0.00025 & 0.00025 & 0.38 \\
3 & 0.00033 & 0.00033 & 0.48 \\
4 & 0.00042 & 0.00042 & 0.62 \\
5 & 0.0005 & 0.0005 & 0.83 \\
\hline
\end{tabular}

Dari data pada tabel 1, alat ini dapat beroperasi pada debit air dan udara minimum $0.00017 \mathrm{~m}^{3} / \mathrm{s}$ atau 600 liter/jam dan maksimum sebesar $0.0005 \mathrm{~m}^{3} / \mathrm{s}$ atau 1800 liter/jam. Sedangkan untuk tekanan minimum yang diijinkan adalah 0.3 bar dan maksimumnya 0.83 bar. Sistem alat aliran dua fase ini bisa bekerja dengan baik pada ketentuan di atas, jika melampui batasan tersebut berakibat pengaliran fluida di seksi uji tidak stabil. Pengujian bisa dilakukan 
dengan memvariasikan debit dari pompa dan kompresor. Misalnya bisa dilakukan pengujian debit air $\left(\mathrm{Q}_{\text {air }}\right)$ konstan pada $0.00017 \mathrm{~m}^{3} / \mathrm{s}$, dengan variasi debit udara ( $Q_{\text {udara }}$ ) berbeda-beda untuk mengetahui pola aliran dan penurunan tekanan (pressure drop) melalui pipa seksi uji horisontal maupun vertikal. Sebagai gambaran disini ditampilkan hasil perhitungan pressure drop pada seksi uji pipa vertikal dengan debit air dan udara sama yaitu $0.00017 \mathrm{~m}^{3} / \mathrm{s}$ pada tabel 2 .

Tabel 2. Hasil perhitungan pressure drop

\begin{tabular}{ll}
\hline Debit air $\left(\mathrm{Q}_{\text {air }}\right)$ & 0,00017 \\
\hline Debit udara $\left(\mathrm{Q}_{\text {udara }}\right)$ & 0,00017 \\
\hline Diameter pipa $(\mathrm{d})$ & $0,008 \mathrm{~m}^{2}$ \\
\hline Luas Penampang $(\mathrm{A})$ & $0,00005 \mathrm{~m}^{2}$ \\
\hline Kecepatan aliran air $\left(\mathrm{V}_{\text {air }}\right)$ & $3,4 \mathrm{~m} / \mathrm{s}$ \\
\hline Kecepatan aliran udara $\left(\mathrm{V}_{\text {udara }}\right)$ & $3,4 \mathrm{~m} / \mathrm{s}$ \\
\hline Laju aliran massa $\left(\dot{m}_{\text {tbtal }}\right)$ & $0,1702 \mathrm{~kg} / \mathrm{s}$ \\
\hline Total fluks massa $(\mathrm{G})$ & 3404,2 \\
\hline Kualitas uap $(\mathrm{x})$ & 0,0012 \\
\hline Kualitas volumetric $(\beta)$ & 0,5 \\
\hline Fraksi hampa $(\propto)$ & 0,49 \\
\hline Kerapatan & 510,6 \\
\hline Viskositas & $1.371,5$ \\
\hline Kecepatan superfisial air $\left(\mathrm{J}_{1}\right)$ & $3,4 \mathrm{~m} / \mathrm{s}$ \\
\hline Kecepatan superfisial udara $\left(\mathrm{J}_{\mathrm{g}}\right)$ & $3,25 \mathrm{~m} / \mathrm{s}$ \\
\hline Kecepatan actual air $\left(\mathrm{U}_{\mathrm{l}}\right)$ & $6,72 \mathrm{~m} / \mathrm{s}$ \\
\hline Kecepatan actual udara $\left(\mathrm{U}_{\mathrm{g}}\right)$ & $6,58 \mathrm{~m} / \mathrm{s}$ \\
\hline Bilangan Reynold air $\left(\mathrm{Re}_{\text {air }}\right)$ & 34.085 \\
\hline Bilangan Reynold udara $\left(\mathrm{Re}_{\mathrm{udara}}\right)$ & 3.342 \\
\hline Faktor gesekan air $\left(\mathrm{Cf} \mathrm{f}_{\text {air }}\right)$ & 0,00195 \\
\hline Faktor gesekan udara $\left(\mathrm{Cf}_{\mathrm{udara}}\right)$ & 0,00981 \\
\hline Tegangan geser air $\left(\tau_{\text {air }}\right)$ & 11,27 \\
\hline Tegangan geser udara $\left(\tau_{\mathrm{udara}}\right)$ & 0,069 \\
\hline Gradient tekanan air $\left(\mathrm{dp}_{\mathrm{d}}\right)$ & 26.997 \\
\hline Gradient tekanan udara $\left(\mathrm{dp}_{\mathrm{air}}\right)$ & 61,2 \\
\hline Preesure drop & 53.319 \\
\hline
\end{tabular}

Alat ini sudah dapat dijadikan media belajar dan praktikum mahasiswa untuk mempermudah memahami materi mata kuliah aliran dua fase yang diberikan oleh dosen. Selain itu juga bisa dijadikan dosen sebagai alat untuk demonstrasi kepada mahasiswa sehingga mempermudah proses belajar mengajar dalam mata kuliah aliran dua fase.

\section{Kesimpulan}

Dari penelitian ini dapat diambil kesimpulan bahwa alat aliran dua fase ini dapat beroperasi pada seksi uji pipa horisontal maupun vertikal dengan debit air dan udara minimum $0.00017 \mathrm{~m}^{3} / \mathrm{s}$ atau 600 liter/jam sedangkan maksimumnya sebesar $0.0005 \mathrm{~m}^{3} / \mathrm{s}$ atau 1800 liter/jam. Untuk tekanan minimum yang diijinkan pada alat ini adalah 0.3 bar dan maksimumnya 0.83 bar. Pengujian bisa dilakukan dengan memvariasikan debit dari pompa dan kompresor. Alat aliran dua fase ini dapat digunakan sebagai media pemebelajaran dan praktikum bagi mahasiswa serta bisa digunakan sebagai alat demonstrasi dosen untuk mempermudah dalam menjelaskan mata kuliah aliran dua fase.

\section{Ucapan terimakasih}

Ucapan terimakasih penulis tujukan kepada LPPM Universitas Muhammadiyah Pontianak yang telah memberikan dana penelitian sejak perencanaan hingga selesai. Ucapan terimakasih juga kepada rekan-rekan yang telah mendukung dan membantu penelitian ini.

\section{Referensi}

[1] Sugiyono P.,2008.Metode Penelitian Kuantitatif Kualitatif dan R\&D, CV. Alfabeta, Bandung.

[2] Munadi Y,2013.Media Pembelajaran Sebuah Pendekatan Baru. Cet. I, GP Press Group, Jakarta.

[3] Brennen C.E.,2005..Fundamentals of multiphase flow, Published by Cambridge University Press, United Kingdom.

[4] M.Massoud.,2005,Engineering Thermofluids, Springer-Verlag Berlin Heidelberg, Germany.

[5] F. Durst, 2008. Fluid mechanics: An introduction to the theory of fluid flows, Springer-Verlag Berlin Heidelberg, Germany.

[6] C.Lu et al., 2017.Frictional pressure drop analysis for horizontal and vertical air-water two-phase flows in different pipe sizes, Nuclear Engineering Design, vol. 332, no. September 2017, pp. 147-161. 
[7] F.A.Hamad, et al, 2017.Investigation of pressure drop in horizontal pipes with different diameters," International Journal Multiphase Flow, vol. 91, pp. 120-129.

[8] Figueiredo,et al,2020.Flow pattern classification in water-air vertical flows using a single ultrasonic transducer, Experimental Thermal and Fluid Science, vol. 119, no. January.

[9] Hanafizadeh,etal,2011. Experimental investigation of air-water, two-phase flow regimes in vertical mini pipe, Scienta Iranica., vol. 18, no. 4 B, pp. 923-929.

[10] S. Rassame and T. Hibiki, 2017.International Journal of Heat and Fluid Flow Drift- fl ux correlation for gas-liquid two-phase flow in a horizontal pipe, International Journal Heat Fluid Flow, vol. 69, no. December 2017, pp. 33-42. 